\title{
BOOK REVIEW - LIVRO*
}

GUÍA PRÁCTICA PARA LA ELIMIN $\triangle$ CIÓN DEL TÉTANOS NEONATAL. Programa Ampliado de Inmunización, Programa de Salud Maternoinfantil y Población. Washington, Organización Panamericana de la Salud; Organización Mundial de la Salud, 1993. viii, 40p. ilust. (Cuaderno Técnico $N^{\circ} 35$ ) ISBN: 927533035 2. Precio: US\$ 5.00

El propósito primordial de la Guía práclica para la eliminación del tétanos neonatal es ofrecer a los médicos $y$ otros integrantes del personal de salud que trabajan para eliminar esta enfermedad a nivel nacional, estatal y local una guía progresiva para organizar y llevar a cabo actividades de control y eliminación. En esta guia se pone de relieve la mejora de la vigilancia a lin de identificar y controlar las áreas de alto riesgo y la ejecución de actividades especiales de inmunización dirigidas a las mujeres en edad fërtil que vivan en esas áreas. El objetivo de dichas medidas es complementar los procedimientos acostumbrados, como la administración de la vacuna triple contra la difteria, la tos ferina y el tétanos (DPT) a los lactantes y a los niños, y de toxoide tetánico (TT) a los escolares y a las mujeres embarazadas.
No se proporciona información detallada sobre la higiene de los procedimientos del parto y del puerperio, ya que este tema se trata más a fondo en otros documentos de la Organización Mundial de la Salud (OMS).

Gran parte de la información contenida en este manual se obtuvo directamente de documentos técnicos preparados por la Organización Panamericana de la Salud (OPS) y otras oficinas regionales de la OMS. Además, se consultaron varios textos y publicaciones. Algunas de estas obras se indican al final de la guía. Los apéndices contienen formularios modelo que pueden copiarse o modificarse según las necesidades especificas del programa.

(OPS/OMS)

\footnotetext{
* Este livro encontra-se na Biblioteca do Instituto de Medicina Tropical de São Paulo.
} 